\title{
Does Salvaging the Environment Require Economic Growth
}

\author{
Anthony A. Noce (Corresponding author) \\ Concordia University, Montreal, Canada \\ E-mail: anoce@alcor.concordia.ca
}

Received: July 19, 2011

Accepted: August 17, 2011

doi:10.5539/jsd.v4n5p3

\begin{abstract}
We examine the determinants of environmental quality by using carbon dioxide emission levels as a proxy for environmental degradation. Our confirmatory, but different approach to analyzing Environmental Kuznets Curve (EKC) patterns in the data yield results that do not always agree with those found in the literature, which itself has no conclusive answer as to whether an EKC exists. We find that a log-linear form best models variations in carbon dioxide $\left(\mathrm{CO}_{2}\right)$ levels for each of the years 1970 and 2007 for the given cross-section of countries. We also note from the cross-sectional regressions that, in 1970, environmental degradation followed a linear trajectory given increasing income levels, but analysis of 2007 data reveals that an N-shaped environmental hypothesis of two inflection points is supported. The panel analysis uncovers similar results including a positive relationship between the Human Development Index (HDI) and environmental degradation; thus leading one to argue that as countries become wealthier, the rate of environmental degradation no longer remains invariable.
\end{abstract}

Keywords: Growth, Environment, Pollution

\section{Introduction}

It is apparent that increased pollution has resulted in ecological degradation which will continue to create sizeable costs for the social order.

Although economic analysis can contribute important answers on the question of which policies can be instituted to achieve optimal levels of pollution, it is still unclear whether a country's increasing wealth will eventually lead to a decrease in pollution intensity. Anecdotally, economic agents avoid compromising the environment when they are less concerned about their own economic survival. That is, increasing disposable household income seems to make economic households more sensitive to environmental issues. This is analogous to households contributing a greater absolute amount of money to charity when their disposable incomes are rising.

At the country-level, one could ask a similar question concerning the level of pollution and a country's level of income. In a paper by Kuznets (1955), a hump-shaped relationship was found between income and the inequality of income. With respect to per capita income and environmental pollution, a number of empirical studies have drawn similar conclusions. These conclusions have led to the Environmental Kuznets Curve (EKC) hypothesis which states that an inverted U-shaped relationship exists between the degradation of environmental quality and growth in per capita income. The EKC hypothesis assumes that environmental quality degrades as income rises, but after reaching a maximum level of pollution environmental quality improves with rising income levels. Reported empirical results described below illustrate that conclusions are ambiguous. Some authors report either monotonically increasing or decreasing relationships between pollution and income or no relationship at all (Egli, 2004). The dependence of environmental degradation on a country's level of income can take several forms: linear, inverted-U, or $\mathrm{N}$-shaped. These relationships are empirically tested in this paper using a longer time series with more country data than found in most of the current literature. Short time periods with large fluctuations in economic growth, especially for developing countries, can disturb true underlying patterns or correlations. It is possible that a longer time period will reveal patterns in environmental degradation that were not clearly formed or evident in shorter time periods.

\section{Literature Review}

The literature on the EKC hypothesis is extensive and varied, but does not form a consensus on the determinants of the levels of environmental pollution. Cole, Elliott and Fredriksson (1997) suggest that the EKC relationship may occur only for pollutants that show short-term impacts at the local level, such as suspended particulate matters (SPM), but not for long-term impacts at the global level such as carbon dioxide. Barbier (1997) notes that the EKC hypothesis seems to be convincing for air pollution indicators with the exception of carbon dioxide. For example, the pollutant sulphur dioxide has been noted to exhibit an EKC by such authors as Selden and Song 
(1994), Grossman and Krueger (1995), Panayotou (1997), and Torras and Boyce (1998). Other authors who do find a correlation between carbon dioxide emissions and gross domestic product (GDP) per capita, such as Moomaw and Unruh (1997), find that three countries in particular- Canada, Luxemburg, and the United Statesexplain the cubic (or N-shaped) relationship between carbon dioxide and income for a subset of 16 Organisation for Economic Co-operation and Development (OECD) countries. Validating the EKC hypothesis is a necessary condition for implementing policies addressing pollution.

A number of factors are put forward to explain the observed inverse-U relationship between environment degradation and income. The relationship between the production and consumption of services is believed to govern changes in the pollution - income relationship. A natural evolution of technology takes place from a minimally polluting agrarian technology to a pollution-intensive manufacturing technology to lastly, less polluting, technology-intensive service economies (Arrow et al., 1995). According to Suri and Chapman (1998), this natural evolution can be reinforced by the exporting of pollution-intensive production processes of advanced economies to poorer, developing economies. Jones and Manuelli (1995) believe that the relationship between environmental degradation and income is determined by market interactions and pollution regulations in an overlapping generations model where the younger generation, through collective decision-making, sets the governing regulations that affect pollution levels.

Some authors note that there are three effects that determine the level of environmental pollution and resource use (Grossman \& Krueger, 1995; Copeland \& Taylor, 2004). The first is that increases in output require more inputs, which results in more emissions. As such, according to Tsurumi and Shunsuke (2010), economic growth exhibits a scale effect that has a negative impact on the environment. The second effect of economic growth can have either a positive or negative impact on the environment through changes in income that may lead to policy changes that in turn lead to changes towards cleaner methods of production. This suggests that the relationship between income and pollution should vary across pollutants because their perceived damage is different (Tsurumi \& Managi, 2010). The third effect of economic growth can also have positive or negative impacts on the environment through a structural change in the economy induced by increasing income levels. That is, as income grows, net household activities can become increasingly or decreasing dirty.

The non-linear relationship between the indicators of environmental pollution and per capita income is usually specified as follows:

$$
Y_{t}=\beta_{0}+\beta_{1} X_{t}+\beta_{2} X_{t}^{2}+\beta_{3} X_{t}^{3}+\beta_{4} Z_{t}+e_{t}
$$

where $Y$ stands for the pollution indicator, such as the level of carbon dioxide,

$\mathrm{X}$ stands for income, such as GDP, and Z stands for other variables that may influence pollution levels. Note that $\mathrm{t}$ denotes a time index and $\mathrm{e}$ is the normally distributed error term.

An EKC results when $\beta 1>0, \beta 2<0$, and $\beta 3=0$. The income level at which environmental degradation begins to decline is called income turning point. When $\beta 1>0, \beta 2<0$ and $\beta 3>0$, an $\mathrm{N}$-shaped pattern is obtained such that there is a second turning point, after which the environmental degradation rises again with increasing income.

\section{Modeling the Relationship}

\subsection{Influencing factors}

Moomaw and Unruh (1997) conclude that an N-shaped curve is more the result of polynomial curve fitting than a reflection of any true structural relation. As will be shown in the results section, the incorporation of a cubic income term will result in the multicollinearity of the income variables (linear, quadratic and cubed). The incorporation of per capita income as an independent variable in single country studies seems undisputed according to Egli (2004), but the selection of explanatory variables is more subjective and may not matter in time-series analysis if they do not change significantly over time.

The role of government in pollution regulation can be influenced by lobby groups whose interests do not lie with stringent environmental regulations, but with the continued use of 'dirtier' forms of energy sources so that profits are maximized. Hence, bribes from both laborers and owners of capital can result in less consideration for social welfare and more regard for cheap resources for production, depending on the corruptibility of a given government. Many studies have noted that corruption can unfavorably affect foreign and domestic investment, foreign aid, and consequently, GDP growth (Lambsdorff, 1999; Fisman \& Svensson, 2000; Wei, 2000). Cole (2006) carries out an empirical analysis on the effect of corruption on pollution given that, as Welsch (2004) maintains, there is uncertainty in the magnitude and significance of the impact of corruption on pollution levels due to few empirical assessments on the subject. Corruption is found by Cole (2006) to have a positive impact on 
air pollution emissions of sulphur dioxide and carbon dioxide. The variable used by Cole (2006) for measuring a country's degree of political corruption is an index based upon expert opinion. In this paper, we will proxy political corruption as well as the altruistic involvement of government in the lives of their citizens by using the human development index (HDI).

The expected change in the concentration of carbon dioxide, with increases in HDI is ambiguous, and will be tested in this paper. It is possible that as governments try to improve the standards of living of their citizens, the country generates more wealth, and in turn, more consumption which leads to increased pollution levels. Alternatively, as governments become less corrupt, HDI tends to increase; they become more "green" and try to minimize adverse environmental effects.

The exporting of pollution-intensive production processes of advanced economies to poorer, developing economies is described in an earlier paragraph as reinforcing the hypothesis that technology moves from a minimally polluting agrarian society to a pollution-intensive manufacturing society. Economies that have low environmental standards in support of their growing and economically important pollution-intensive manufacturing sector are seen to possess a comparative advantage. This comparative advantage can shift trade patterns in favor of heavily polluting countries. Therefore, if multinational firms who are engaged in highly polluting activities relocate their manufacturing activities to countries with lower environmental standards, then these highly polluting economies should be recipients of relatively larger inflows of foreign direct investment (FDI). This paper includes in its model net flows of per capita FDI as a predictor of pollution.

Vincent (1997) finds, in his study of Malaysia, that rapid urbanization as a result of increasing income levels is responsible for increasing concentrations of acid and ammonia in municipal waters. Although the study focuses on water pollution, it is conceivable that air pollution can be negatively affected in the same manner. Thus, a country's percentage of urbanization is incorporated in this paper's model.

\subsection{The Statistical Model}

This paper carries out a four-fold comparison of methodologies to test whether an EKC relationship does exist between the environmental pollutant, carbon dioxide, and income at the global level. This four-fold comparison as such, using all countries for which data are available from 1970 to 2007 has, to this author's knowledge, not been carried out. It is also the aim of this paper to determine whether a cubic relationship exists between carbon dioxide and income and to expand the sample size to include all countries for which data are available. The four analyses include two cross-sectional regressions for the years 1970 and 2007, respectively, one time-series dynamic model for all countries for all years and one panel data analysis. The motivation of the four analyses is threefold: (1) to determine whether an EKC pattern exists for the given set of countries for each of the independent years, 2007 and 1970, respectively; (2) to determine whether aggregated world totals exhibit a EKC pattern for all years from 1970 to 2007 using an autoregressive equation; (3) to compare all of the results from motivations (1) and (3) to each other and to a further panel analysis using all countries for all years. Note that both a dynamic time-series model analysis and a panel analysis are carried out because the former uses, by construct, only aggregated world data (hence treating the world as a single economic system or country, while the latter is essentially a pooled cross-section analysis for all countries and all years simultaneously.

Three specifications for EKCs for pollutants (in our case, carbon dioxide) are portrayed in the literature: linear, quadratic (inverted-U), and cubic (N-shaped). Therefore, we have the following partial model (the error is excluded for the moment since the equation does not represent the full model employed in the study):

$$
\mathrm{CO}_{2}=\mathrm{Y}=\beta_{0}+\beta_{1} \mathrm{X}_{1}+\beta_{2} \mathrm{X}_{1}{ }^{2}+\beta_{3} \mathrm{X}_{1}^{3} \text {, where } \mathrm{X}_{1} \text { is the GDP per capita. }
$$

To re-iterate, in the linear case, $\beta_{1}>0$ and $\beta_{2}=\beta_{3}=0$. In the quadratic case where an inverted-U relationship exists between carbon dioxide and GDP per capita, $\beta_{1}>0, \beta_{2}<0$, and $\beta_{3}=0$. In the cubic case, an N-shaped relationship exists between carbon dioxide and GDP per capita, where, $\beta_{1}>0, \beta_{2}<0$, and $\beta_{3}>0$. Adding all the predictor variables described above, we arrive at the tested models:

(i) Cross-sectional ordinary least squares (OLS) for year $=2007$ :

$$
\mathrm{Y}_{\mathrm{i}}=\beta_{0}+\beta_{1} \mathrm{X}_{\mathrm{i} 1}+\beta_{2} \mathrm{X}_{\mathrm{i} 1}^{2}+\beta_{3} \mathrm{X}_{\mathrm{i} 1}^{3}+\beta_{4} \mathrm{X}_{\mathrm{i} 2}+\beta_{5} \mathrm{X}_{\mathrm{i} 3}+\beta_{6} \mathrm{X}_{\mathrm{i} 4}+\varepsilon_{\mathrm{i}}
$$

where $\mathrm{Yi}$ is a country level of carbon dioxide per capita, $\mathrm{X}_{\mathrm{i} 1}$ is the GDP per capita (2007, current United States dollars (USD)) for the $i$ th country, $\mathrm{X}_{\mathrm{i} 2}$ is the percent urbanization (2007) for the $i$ th country, $\mathrm{X}_{\mathrm{i} 3}$ is the net FDI (2007, current USD) for the $i$ th country, and $\mathrm{X}_{\mathrm{i} 4}$ is the HDI score (2007) for the $i$ th country.

(ii) Cross-sectional OLS for year $=1970$ :

$$
\mathrm{Y}_{\mathrm{i}}=\beta_{0}+\beta_{1} \mathrm{X}_{\mathrm{i} 1}+\beta_{2} \mathrm{X}_{\mathrm{i} 1}^{2}+\beta_{3} \mathrm{X}_{\mathrm{i} 1}^{3}+\beta_{4} \mathrm{X}_{\mathrm{i} 2}+\varepsilon_{\mathrm{i}}
$$


where Yi is a country level of carbon dioxide per capita, $X_{\mathrm{i} 1}$ is the GDP per capita (1970, current USD) for the $i$ th country, and $\mathrm{X}_{\mathrm{i} 2}$ is the percent urbanization (1970) for the $i$ th country.

Note that the HDI scores were unavailable for 1970 and the FDI amounts were not available for many countries.

(iii) Dynamic model for world totals for years 1970 to 2007 :

$$
Y_{t}=\beta_{0}+\beta_{1} X_{t 1}+\beta_{2} X_{t 1}^{2}+\beta_{3} X_{t 1}^{3}+\beta_{4} X_{t 2}+\beta_{5} Y_{t-1}+\varepsilon_{i}
$$

where $\mathrm{Y}_{\mathrm{t}}$ is a world level of carbon dioxide per capita, $\mathrm{X}_{\mathrm{t} 1}$ is the yearly world GDP per capita for the time period $t$, $\mathrm{X}_{\mathrm{t} 2}$ is the world percent urbanization for the time period $t$, and $\mathrm{Y}_{\mathrm{t}-1}$ is the one-year lag value for world GDP per capita.

Note that HDI score is not used as there is no aggregate world HDI score.

(iv) Panel analysis:

$$
Y_{i t}=\beta_{0}+\beta_{1} X_{i t 1}+\beta_{2} X_{i t 1}{ }^{2}+\beta_{3} X_{i t 1}{ }^{3}+\beta_{4} X_{i t 2}+\beta_{5} X_{i t 3}+\beta_{6} X_{i t 4}+\beta_{7} X_{i 3} X_{i t 4}+\varepsilon_{i t}
$$

where $Y_{i t}$ is a country's level of carbon dioxide per capita, $X_{i t 1}$ is the GDP per capita (current USD) for the $i$ th country and time $t, X_{\mathrm{it} 2}$ is the percent urbanization for the $i$ th country and time $t, X_{\mathrm{it} 3}$ is the net FDI score (current USD) for the $i$ th country and time $\mathrm{t}$, and $\mathrm{X}_{\mathrm{it} t}$ is the HDI score for the $i$ th country and time $\mathrm{t}$.

\subsubsection{Model Selection}

Given that this is a confirmatory observational study, the control variables are chosen on the basis of prior knowledge and empirical results of EKC theory; albeit, some of the variables have been modified. Unlike exploratory observational studies, the number of starting variables in this study is not very large. Also, unlike exploratory observational studies, forward stepwise regression and all-possible-regressions procedures are not necessary to reduce the pool of potential $\mathrm{X}$ variables for a more parsimonious model. Thus, our model will be selected based on the results of transformations, diagnostics and remedial measures performed in the following sections so that the least squares estimators are unbiased and have minimum variance. The linear model assumptions of homoskedasticity of the residuals, normally-distributed residuals, linearity and the condition that none of the independent variables is an exact linear combination (nor highly correlated with) the other independent variables will be tested.

\subsection{Data}

Data for over 140 countries are collected (see Tables 1 and 2), although not all countries are incorporated in the analyses due to missing data. Only countries for which completed data are available are included. The dependent variable data are obtained from World Bank database for development data using metric tonnes per capita as the measurement units for carbon dioxide.

The measure of country's income used in this study is GDP per capita in current (reference year is 2005) U.S. dollars. The income data are drawn from the Penn World Tables available from the Center for International Comparisons of Production, Income and Prices, University of Pennsylvania. The measure of GDP from the Penn World Tables is widely employed in the literature and country comparisons over time are easily made.

The measure of a country's level of development is measured using Human Development Index (HDI). HDI measures development by combining indicators of life expectancy, educational attainment and income into a single statistic that serves as a frame of reference for both social and economic development. The HDI sets a minimum and a maximum for each dimension, called goalposts, and then shows where each country stands in relation to these goalposts, expressed as a value between 0 and 1 . HDI data is available from 1980 onwards from Human Development reports (United Nations Development Program).

The urbanization dummy variable is derived using World Bank population estimates and urban ratios from the United Nations World Urbanization Prospects. The data are available from the World Bank database for development.

Foreign Direct Investment (FDI) data are obtained from the United Nations Conference on Trade and Development (UNCTAD) and available from 1970 onwards. FDI inflows and outflows comprise capital provided (either directly or through other related enterprises) by a foreign country in a reporting economy. The FDI flows are measured in millions of current US dollars and current exchange rates. 


\section{Results and Discussion}

\subsection{Cross-sectional Analyses for 2007}

Regression results for 2007 are illustrated in Table 3. The model is significant at the $5 \%$ level (F-statistic $=75.8)$ and all estimated coefficients, except $b_{4}, b_{6}$ and the constant are significant at the $5 \%$ level. The signs of $b_{1}, b_{2}$, and $\mathrm{b}_{3}$ are positive, negative, and positive, respectively. This indicates support for an $\mathrm{N}$-shaped curve described above. The model seems to explain approximately $77 \%$ of the variation in the concentration of carbon dioxide. The Breusch-Pagan (BP) test is used to verify the presence of heteroskedasticity. The test statistic, $\chi_{\mathrm{BP}}^{2}$, is as follows: $\chi_{\mathrm{BP}}^{2}=(\mathrm{SSR} * / 2) /(\mathrm{SSE} / \mathrm{n})^{2}=(43634 / 2) /(1763 / 141)^{2}=139>\chi_{7,0.95}^{2}=12.59$ (critical value) where SSE is the sum of squared errors from the OLS regression and SSR* is obtained from a regression of the squared errors from the original OLS regression and the explanatory variables. Given the null hypothesis of constant error variance, we reject it and conclude, at the 5\% level, that there is evidence to support the claim of heteroskedasticity. Furthermore, the variance inflation factor (VIF) values for $\mathrm{X}_{1}, \mathrm{X}_{1}{ }^{2}$, and $\mathrm{X}_{1}{ }^{3}$ all greatly exceed 10 . This indicates that serious multicollinearity problems exist with this specified model.

The method of least squares is best under the assumption of normality. We test the model above for normality using the Kolmogorov-Smirnov test and the Shapiro-Wilk test. The tests reveal non-normal errors. A number of alternative functional forms of the regression model are used to arrive at one that best describes the relationship between carbon dioxide and the predictor variables and where the variance of error terms is constant, and serious multicollinearity is reduced. To resolve the issues of non-normality and unequal variances in the error terms that were encountered above, different transformations on $\mathrm{Y}$ are carried out. The following transformations are used and the model is then re-estimated:

$$
\begin{aligned}
& \text { Transformation 1: } \ln \left(\mathrm{Y}_{\mathrm{i}}\right)=\beta_{0}+\beta_{1} \mathrm{X}_{\mathrm{i} 1}+\beta_{2} \mathrm{X}_{\mathrm{i} 1}{ }^{2}+\beta_{3} \mathrm{X}_{\mathrm{i} 1}{ }^{3}+\beta_{4} \mathrm{X}_{\mathrm{i} 2}+\beta_{5} \mathrm{X}_{\mathrm{i} 3}+\beta_{6} \mathrm{X}_{\mathrm{i} 4} \\
& \text { Transformation 2: } 1 / \mathrm{Y}_{\mathrm{i}}=\beta_{0}+\beta_{1} \mathrm{X}_{\mathrm{i} 1}+\beta_{2} \mathrm{X}_{\mathrm{i} 1}{ }^{2}+\beta_{3} \mathrm{X}_{\mathrm{i} 1}{ }^{3}+\beta_{4} \mathrm{X}_{\mathrm{i} 2}+\beta_{5} \mathrm{X}_{\mathrm{i} 3}+\beta_{6} \mathrm{X}_{\mathrm{i} 4} \\
& \text { Transformation 3: } \mathrm{Y}^{1 / 2}{ }_{\mathrm{i}}=\beta_{0}+\beta_{1} \mathrm{X}_{\mathrm{i} 1}+\beta_{2} \mathrm{X}_{\mathrm{i} 1}{ }^{2}+\beta_{3} \mathrm{X}_{\mathrm{i} 1}{ }^{3}+\beta_{4} \mathrm{X}_{\mathrm{i} 2}+\beta_{5} \mathrm{X}_{\mathrm{i} 3}+\beta_{6} \mathrm{X}_{\mathrm{i} 4}
\end{aligned}
$$

Each of the transformations is estimated separately using the data for the complete sample of 141 countries. Table 4 illustrates the results of the regressions from the transformations. The BP-test for the transformation 1 gives a value of 13.8 which leads to acceptance of the null hypothesis of constant variance at the $10 \%$ significance level. The BP-test for the transformation 2 rejects the null hypothesis of constant error variance at the $5 \%$ and $10 \%$ level. The BP-test for the transformation 3 reveals a chi-square value of 60.6 , which indicates that heteroskedasticity exists at the 5\% significance level.

Transformations on Y do not affect the VIF values. The transformations were meant to stabilize the error variance and possibly normalize the residuals, but were not intended to handle the presence of multicollinearity. We also observe that the F-statistic is significant at the 5\% level for all transformations. The coefficient of determination and consequently, the adjusted $\mathrm{R}^{2}$ value for each respective regression show that the transformation 1 (i.e. $\ln \mathrm{Y}$ ) is the model that best explains the variation in per capita carbon dioxide levels and does not exhibit heteroskedasticity among the errors. In addition, all the coefficients are significant at the 5\% level for the model represented by transformation 1. Given the lack of heteroskedasticity, the appropriateness of the signs of the coefficients related to income and the greatest value for goodness of fit, we conclude that the model resulting from transformation 1 should be used to draw inferences.

The estimation results of our transformation are presented above and our regression equation can be illustrated as follows:

$$
\mathrm{Y}_{\mathrm{i}}{ }^{*}=-3.386+0.00016 \mathrm{X}_{\mathrm{i} 1}-\left(3.7 \times 10^{-9}\right) \mathrm{X}_{\mathrm{i} 1}{ }^{2}+\frac{\left(2.45 \times 10^{-14}\right) \mathrm{X}_{\mathrm{i} 1}{ }^{3}+0.009 \mathrm{X}_{\mathrm{i} 2}+\left(5.63 \times 10^{-12}\right) \mathrm{X}_{\mathrm{i} 3}+3.85 \mathrm{X}_{\mathrm{i} 4} \text {, where } \mathrm{Y}^{*}=}{\ln \left(\mathrm{CO}_{2}\right) .}
$$

The model is found to be significant overall at the $5 \%$ level and that the regression explains $84.8 \%$ of the total variation in per capita carbon dioxide levels. The t-tests for all $\beta$ coefficients are significant at the $5 \%$ level. Given that our model is a semi-log model (log-linear), we interpret that, on average, for $\mathrm{X}_{2}$, a 0.009 percentage increase in per capita carbon dioxide emissions results from a one percentage point increase in a country's level of urbanization, holding all else constant. Similarly, when controlling for other variables, a one unit increase in the HDI index will cause, on average, a 3.85\% increase in the per capita emission of carbon dioxide.

The sign of $b_{2}$ is consistent with Vincent (1997), who found that rapid urbanization leads to higher pollution levels. Note, however, Vincent's (1997) dependent variable is water, not air, pollution. Although it is quite small (but statistically significant), the coefficient for FDI does have a sign consistent with the theory, that increasing inflows of FDI lead to increasing pollution levels. Our use of HDI is novel; therefore, comparison of the 
coefficient with other studies is not possible. However, we speculated earlier that a positive coefficient may indicate that as governments try to improve the standards of living of their citizens, the country generates more wealth, and in turn, more consumption which leads to increased pollution levels.

With respect to the income variable, we note that coefficients alternate in their signs: positive-negative-positive, which supports the N-shape environmental hypothesis of two inflection points. Hence for this cross-sectional group of countries for 2007, increasing per capita GDP levels increase per capita carbon dioxide emissions at a decreasing rate until a local maximum is reached from which further increases in income will increase emissions at an increasing rate. The $\mathrm{N}$-shaped relationship (i.e. cubic relationship) between income and environmental degradation is significant at the 5\% level. However, it is only applicable to year 2007.

\subsection{Cross-sectional Analysis for 1970}

Using the same (general) model as that of 2007, we investigate whether this conclusion holds for a cross-sectional analysis for the year 1970. Note that the only non-income variable retained is percentage of urbanized population. The HDI index was not available in 1970 and the net FDI values were generally missing from the data set for the same year. Since two of the control variables are missing, diagnostics for the model transformation, as before, will be performed. Table 4 summarizes the results of the five regressions for 1970 . Table 5 summarized the BP-test results.

Only the log-linear transformation had both normally distributed errors and no heteroskedasticity present. The log-linear model also has one income coefficient, $b_{1}$, which is significant at the $5 \%$ level. Whereas the untransformed model and the squared model have significant coefficients for all three income coefficients, their signs are not as expected. This result of unexpected coefficients could be a casual indicator of multicollinearity, which is present in all of the models. Since multicollinearity increases the variances and standards errors of the estimated coefficients, we have the possibility that our sampling distribution is spread such that it straddles zero and produces an unexpected sign. Another frequent source that may result in an unexpected sign for a coefficient of a relevant independent variable is an omitted variable. Given the literature on EKC, it is possible that we may have a bias due to an omitted variable. However, determining which variable may have been omitted would be a daunting exercise. Thus, we note that the log-linear model has the expected sign for the income coefficient without any violations of the classic regressions assumptions except that for multicollinearity. The log-linear model, in addition, explains $78.2 \%$ of the explained variation in per capita carbon dioxide emissions.

Concluding that the log-linear form once again best models variations in carbon dioxide levels for 1970 for the given cross-section of countries, we interpret that, on average, for $\mathrm{X}_{2}$, one percentage point increase in a country's level of urbanization, holding all else constant, leads to a 0.032 percentage increase in per capita carbon dioxide emissions. We note that although a direct comparison cannot be made with the regression model for 2007, a 0.032 percent increase in per capita carbon dioxide emissions in 1970 is about a 3.6-fold increase in the effect that urbanization has in 2007. This result seems plausible as the effect of urbanization on environmental pollution may have decreased given that, for most countries, urbanization levels are starting to or have reached a saturation point. The regression using 2007 data led one to conclude that there is support for an $\mathrm{N}$-shaped environmental hypothesis. However, the model regression for 1970 shows that environmental degradation follows a linear trajectory. That is, increasing per capita GDP levels increase per capita carbon dioxide emissions at a constant rate rather than at decreasing rate until a local maximum is reached from which further increases in income will increase emissions at an increasing rate. Are these two conclusions at odds with one another or can they be reconciled? One can argue that the relationship between the levels of pollution emissions and those of national income evolved over time such that the rate of environmental degradation increased at a constant rate in 1970, but that as countries became generally richer by 2007 the rate of environmental degradation no longer remained invariable. This conclusion would not be in contradiction with the inconsistent conclusions found in the literature. For example, Cole et al. (1997) suggest that EKC relationship may occur only for pollutants that show short-term impacts at the local level, such as suspended particulate matters, but not for long-term impacts at the global level such as carbon dioxide. Barbier (1997) notes that the EKC hypothesis seems to be convincing for air pollution indicators with the exception of carbon dioxide. Arrow et al. (1995) believe that the relationship is appropriate for only a few pollutants such as sulphur dioxide and therefore the EKC hypothesis, cannot be used to theorize, generally, about the environmental implications of economic growth. In order to determine whether time influences the relationship between per capita carbon dioxide emissions and per capita GDP, we will conduct a second two-fold investigation. That is, we will investigate (1) a simple dynamic time series for aggregated world data and (2) a panel analysis for all countries for the years 1970 to 2007 . 


\subsection{Dynamic Time Series, 1970-2007}

In order to determine the influence of income on carbon dioxide emissions over time, we will first investigate whether all countries as a whole (i.e. using aggregated global GDP per capita and per capita carbon dioxide emissions) can adequately describe the EKC hypothesis using a time series model. The dynamic model used is one in which the dependent variable, per capita $\mathrm{CO}_{2}$ emissions, is a function of the current value of GDP per capita and a lagged value of per capita $\mathrm{CO}_{2}$ emissions themselves. Thus, the dynamic model for world totals for years 1970 to 2007 is as follows:

$$
Y_{t}=\beta_{0}+\beta_{1} X_{t 1}+\beta_{2} X_{t 1}^{2}+\beta_{3} X_{t 1}^{3}+\beta_{4} X_{t 2}+\beta_{5} Y_{t-1}+\varepsilon_{i}
$$

Where $Y_{t}$ is a world level of carbon dioxide per capita (metric tonnes per capita), $X_{t 1}$ is the yearly world GDP per capita (current USD, millions) for the time period $t, X_{t 2}$ is the world percent urbanization for the time period $t$, and Yt-1 is the one-year lag value for world level of carbon dioxide per capita. ( $\mathrm{t}$ starts at 1971 such that $\mathrm{t}-1=$ $1970 ; n=37)$. Note that HDI score is not used as there is no aggregate world HDI score. The results are illustrated in Table 6. We use a dynamic model in order to avoid certain problems that can occur with ad hoc distributed lag equations. That is, it is likely that the impact of the independent variable, income, is distributed over a number of time periods so that GDP per capita affects per capita carbon dioxide emissions in future time periods as well as in current time periods. Using an ad hoc distributed lag equation would dramatically decrease our degrees of freedom - something we wish to avoid given that our sample size is now 37 (time periods). It is also anticipated that problems associated in the previous analyses with multicollinearity will disappear with a dynamic time series model. We begin with two regressions on our dynamic time series model. The first is a simple straightforward regression of equation (3) and the second, due to the results in the previous cross-sectional analyses, a regression of equation (3) where the dependent variable is the natural logarithm of per capita carbon dioxide emissions.

The results indicate that both versions of equation (3) yield statistically significant models (F-test); however, none of the coefficients are statistically significant (t-test) except that for the lagged dependent variable. It is possible that in our dynamic equations, serial correlation of the error terms is causing bias in the coefficient estimates. Since our model contains a lagged dependent variable as an independent variable, it is likely that it is serially correlated with the error term thus rendering our hypotheses testing invalid. Using the log-linear form for consistency, we use the Lagrange Multiplier Serial Correlation (LMSC) test to determine whether serial correlation exists in our dynamic model. The LMSC test uses the residuals from the initial dynamic regression as the dependent variable in an auxiliary equation that includes all the original independent variables plus the lagged residuals, as independent variables. We use the test statistic $n\left(R^{2}\right)=(37)(0.159)=5.724$, where $n$ is the sample size and $\mathrm{R}^{2}$ is the unadjusted coefficient of determination obtained from the LMSC regression described in the preceding sentence, to test whether the coefficient for the lagged error term is zero. The test statistic has a chi-square distribution with one degree of freedom such that the critical value, at $95 \%$ significance, is 3.84 . With a value of 5.724, we reject the null hypothesis that the coefficient for the lagged term is zero and conclude that there is serial correlation in the original equation. Note that removal of the variable, URBAN, still results in serial correlation.

Correcting for serial correlation in our dynamic model may prove difficult since it may be caused by one or more reasons: omission of a relevant variable or improper lag structure - both of which are difficult to remedy. More likely our sample size is too small imparting bias in our estimates. However, if our underlying theory - that the impact of the independent variable, income, is distributed over a number of time periods so that GDP per capita affects per capita carbon dioxide emissions in future time periods as well as in current time periods - is incorrect, our use of a dynamic time series model is not valid. As such, we drop the lagged dependent-independent variable and re-estimate a non-dynamic time series model. The results (Table 6) show, once again, that the model is significant overall, but none of the coefficients (except that for urbanization) are significant at the 5\% level. Although the t-tests are not over-inflated, we test our model to determine whether we have a spurious correlation caused by non-stationary time series.

To ensure that the model we used is not spurious, we test for non-stationarity via the Dickey-Fuller test, which examines the hypothesis that the lagged dependent variable has a unit root (i.e. follows a random walk and is non-stationary) and as a result, should be expressed in first difference form. We first define the variable $\Delta \mathrm{Y}_{\mathrm{t}}=$ $\mathrm{CO}_{2 \mathrm{t}}-\mathrm{CO}_{2(\mathrm{t}-1)}$ such that our Dickey-Fuller test (non intercept) is $\Delta \mathrm{Y}_{\mathrm{t}}=\beta_{1} \mathrm{Y}_{\mathrm{t}-1}+\mathrm{e}_{\mathrm{t}}$. The null hypothesis is that $\mathrm{Y}_{\mathrm{t}}$ contains a unit root (i.e. is non-stationary, $\beta_{1}=0$ ). The alternative hypothesis is $\beta_{1}<0$ ). The regression results (Table 7) show that $\beta_{1}=0.004$ and the calculated $t$-value to be 1.003 . The critical t-value is -2.86 ; thus, we do not reject the null hypothesis and conclude that $Y_{t}$ has a unit root. Furthermore, we also use a Dickey-Fuller test to 
test the equation with an intercept and a time trend as follows: $\Delta \mathrm{Y}_{\mathrm{t}}=\beta_{0}+\beta_{1} \mathrm{Y}_{\mathrm{t}-1}+\beta_{2} \mathrm{t}+\mathrm{e}_{\mathrm{t}}$. We have the following result: $\beta_{1}=-0.100$, t-value $=-0.966$ and $\beta_{2}=0.001$, t-value $=0.807$. Once again, we do not reject the null hypothesis and conclude that the dependent variable contains a unit root.

The two Dickey-Fuller tests reveal non-stationary in our time-series. One can use first-differences in the dependent variable and the independent variables to convert the non-stationary series to a stationary one. However, this cannot be done until the residuals are tested for co-integration - where the dependent and independent variables are tested for a long-term equilibrium relationship. To illustrate, we perform the co-integration test as follows:

(a) OLS estimate for the equation: $\Delta Y_{t}=\beta_{0}+\beta_{1} X_{1 t}+\beta_{2} X_{1 t}^{2}+\beta_{3} X_{1 t}^{3}+e_{t}$,

(b) Error terms are saved; the regression is estimated: $e_{t}=\beta_{0}+\beta_{1} X_{1 t}+\beta_{2} X_{1 t}{ }^{2}+\beta_{3} X_{1 t}{ }^{3}+u_{t}$,

(c) Dickey-Fuller test is performed on the residuals.

A Dickey-Fuller test performed on the residuals indicate that at the 5\% level that the least squares residuals are non-stationary (and thus first differences estimation can be used), but at the $10 \%$ level, we reject the null hypothesis that the least square residuals are non-stationary, and conclude that they are stationary. This indicates that there may be a long-run, equilibrium between income and per capita carbon dioxide levels. However, since our sample size is small and that the results are not without problems, we are cautious about this interpretation. As such, we carry out a panel regression in the following section in order to determine whether there is further evidence to support the conclusions of the previous analyses.

\subsection{Panel Analysis, 1970-2007}

In this section we pool the data for all years for all countries. Given that we are interested in the effect of every independent variable described above, in addition to income, on the level of per capita carbon dioxide emissions, it was necessary to use some discretion in order to complete the data set for which some values were unavailable for earlier years. That is, we want our conclusions to apply to as many countries as possible for as many years as possible. As such, for any missing values of the independent variables "HDI index", "percentage urbanization", the earliest available year of data was used for missing prior years of data. If data for any one country was highly fragmented during the 1970 to 2007 time period, then that country was discarded. Table 2 lists the countries that are included in the analysis. Lastly, the data are arranged as stacked time series with 101 cross-sectional units and 38 time periods for a total of 3795 observations. Mathematically, we run a fixed-effects analysis (this is implemented by subtracting the group or unit means from the original data) using gretl, a cross-platform software package for econometric analysis, on the following model:

$$
\mathrm{Y}_{\mathrm{it}}=\beta_{0}+\beta_{1} \mathrm{X}_{\mathrm{it1} 1}+\beta_{2} \mathrm{X}_{\mathrm{it} 1}^{2}+\beta_{3} \mathrm{X}_{\mathrm{it} 1}^{3}+\beta_{4} \mathrm{X}_{\mathrm{it} 2}+\beta_{5} \mathrm{X}_{\mathrm{it} 3}+\beta_{6} \mathrm{X}_{\mathrm{it} 4}+\beta_{7} \mathrm{X}_{\mathrm{i} 3} \mathrm{X}_{\mathrm{it} 4}+\varepsilon_{\mathrm{it}}
$$

where $Y_{i t}$ is a country level of carbon dioxide per capita, $X_{i t 1}$ is the GDP per capita (current USD) for the $i$ th country and time $t, X_{\mathrm{it} 2}$ is the percent urbanization for the ith country and time $t, X_{\mathrm{i} t 3}$ is the net FDI (current USD) for the ith country and time $t$, and $\mathrm{X}_{\mathrm{it}}$ is the HDI score for the ith country and time $\mathrm{t}$.

With the above model, we assume that the usual OLS assumptions hold, that the intercept is constant across different observations and cross-sectional units, and through time. We proceed with the above fixed effects model to avoid specification bias issues and for ease of interpretation. The results are summarized in Table 8 . Note that, unlike the cross-sectional regression carried out above, the natural logarithm of per capita carbon dioxide emissions were not used in the final regression as they did not yield a favorable coefficient of determination. Further, note that we do not include panel analysis results from lagged income variables as this inclusion resulted in a matrix that was not positive definite. Thus the results are not robust to lagged income variables. This is not surprising given that the two Dickey-Fuller tests performed in the previous analysis revealed non-stationary in our time-series.

The model is found to be significant overall at the 5\% level and that the regression explains $83 \%$ of the total variation in per capita carbon dioxide levels. The t-tests for all $\beta$ coefficients are significant at the $5 \%$ level except that for FDI. Given that the coefficients for income are statistically significant, we also note that they follow a positive, negative, positive pattern which indicates that the data follow an N-shaped pattern rather than an EKC pattern. Although most panel, fixed effects regressions found in the literature did not follow an inverted U-shape relationship between income and carbon dioxide emissions, Galeotti et al. (2006) find that for 1960-1997 for OECD, and 1971-1997 for non-OECD panel regressions results depend on the data sampled and the estimation method.

We interpret that, on average, for the variable "percent urbanization", a one percentage point increase in 
urbanization results in decreases rather than increases in per capita carbon dioxide emissions when controlling for income, FDI, and HDI. Similarly, increases in HDI result in increases in per capita carbon dioxide emissions, holding all else constant. The latter finding supports our earlier speculative discussion that as governments try to improve the standards of living of their citizens, the country generates more wealth, and in turn, more consumption which leads to increased pollution levels. Although the absolute effect is small, the former finding is statistically significant, but the sign is not as expected. It is unclear whether this is a result of an omitted variable since the overall fit of the regression is good. However, Torras and Boyce (1998) explain that although "urbanization is often associated with greater levels of pollution, it may also facilitate some environmental improvements, for example, through economies of scale in the provision of sanitation facilities" and that "richer countries, which tend to have relatively cleaner urban air and relatively cleaner river basins, also have relatively more stringent environmental standards and stricter enforcement of their environmental laws than the middle-income and poorer countries".

\section{Conclusion}

Environmental degradation follows a linear trajectory given increasing income levels using 1970 data, but analysis of 2007 data reveals that an $\mathrm{N}$-shaped environmental curve. This may indicate that although reaching a certain level of income will reduce the rate of environmental degradation, increasing wealth may inevitably return a country to increasing rates of environmental degradation. Significant non-income explanatory variables such as urbanization and HDI show opposite effects on the environment. Our panel analysis indicates that improvements in HDI have a negative effect on environmental quality while urbanization has a positive effect on environmental quality. According to the results, the EKC hypothesis does not apply for either the two end point years or the time series as a whole. Thus, one could stipulate that salvaging the environment requires that economic growth, as is currently defined and understood, ceases. Politically, this is not an option. Rather, policies regarding environmental quality should stress sustainable development in sprawling metropolitan areas and not be coupled to GDP growth. This is important in developed countries, but likely more so in developing nations since environmental degradation for the latter group will almost certainly follow a monotonically increasing curve with respect to income. For these countries, environmental improvement will be accentuated by economic growth and thus policies should ensure they become rich quickly, but in conjunction with 'green' city initiatives; that is, with strong environmental standards and laws so that their trajectory follows, at worst, an inverted $-\mathrm{U}$ rather than an N-pattern.

\section{References}

Arrow, K., Bolin, B., Costanza, R., Dasgupta, P., Folke, C., Holling, C., et al. (1995). Economic growth, carrying capacity, and the environment. Science, 268, 520-21.

Barbier, E. B. (1997). Introduction to the environmental Kuznets. Environment and Development Economics, 2, 369-81, doi:10.1017/S1355770X97000193, http://dx.doi.org/10.1017/S1355770X97000193

Cole, M. A., Rayner, A. J. \& Bates, J. M. (1997). The environmental Kuznets curve: an empirical analysis. Environment and Development Economics, 2(4), 401-16.

Cole, M. A., Elliott, R. J. R. \& Fredriksson, P. (2006). Endogenous Pollution Havens: Does FDI Influence Environmental Regulations? Scandinavian Journal of Economics, 108(1), 157-78, doi:10.1017/S1355770X97000211, http://dx.doi.org/10.1017/S1355770X97000211

Copeland, B. \& Taylor, S. (2004). Trade, growth and the environment. Journal of Economic Literature, 42, 7-71.

Egli, H. (2004). The Environmental Kuznets Curve: Evidence from Time Series Data for Germany (Swiss Federal Institute of Technology, Zurich, Working Paper).

Fisman, R. \& Svensson, J. (2000). Are corruption and taxation really harmful to growth? Firm level evidence. World Bank Policy Research Working Paper Series, vol. 2485.

Galeotti M., Lanza A. \& Pauli F. (2006). Reassessing the environmental Kuznets curve for $\mathrm{CO}_{2}$ emissions: a robustness exercise. Ecological Economics, 57, 152-63, doi:10.1016/j.ecolecon.2005.03.031, http://dx.doi.org/10.1016/j.ecolecon.2005.03.031

Grossman, G. M. \& Krueger, A. B. (1995). Economic growth and the environment. Quarterly Journal of Economics, 110, 353-77.

Jones, L. E. \& Manuelli, R. E. (1995). A positive model of growth and pollution controls (National Bureau of Economic Research Working Paper 5205). 
Kuznets, S. (1955). Economic growth and income inequality. American Economic Review, 45(1), 1-28.

Lambsdorff, J. G. (1999). Corruption in empirical research: a review (Transparency International Working Paper).

Moomaw, W. R. \& Unruh, G. C. (1997). Are Environmental Kuznets Curves misleading us? The case of CO2 emissions. Environment and Development Economics, 2(4), 451-63, doi:10.1017/S1355770X97000247, http://dx.doi.org/10.1017/S1355770X97000247

Panayotou, T. (1997). Demystifying the environmental Kuznets curve: turning a black box into a policy tool. Environment and Development Economics, 2, 465-84, doi:10.1017/S1355770X97000259, http://dx.doi.org/10.1017/S1355770X97000259

Selden, T. M. \& Song, D. (1994). Environmental quality and development: is there a Kuznets curve for air pollution emissions? Journal of Environmental Economics and Management, 27, 147-62, doi:10.1006/jeem.1994.1031, http://dx.doi.org/10.1006/jeem.1994.1031

Suri, V. \& Chapman, D. (1998). Economic growth, trade and energy: implications for the environmental Kuznets curve. Ecological Economics, 25(2), 195-208, doi:10.1016/S0921-8009(97)00180-8, http://dx.doi.org/10.1016/S0921-8009(97)00180-8

Torras, M. \& Boyce, J.K. (1998). Income, inequality, and pollution: a reassessment of the environmental Kuznets Curve. Ecological Economics, 25(1), 147-160, doi:10.1016/S0921-8009(97)00177-8, http://dx.doi.org/10.1016/S0921-8009(97)00177-8

Tsurumi, T. \& Managi, S. (2010). Decomposition of the environmental Kuznets curve: scale, technique, and composition effects. Environmental Economics and Policy Studies, 11, 19-36, doi:10.1007/s10018-009-0159-4, http://dx.doi.org/10.1007/s10018-009-0159-4

Vincent, J. R. (1997). Testing for Environmental Kuznets Curves within a developing country. Environment and

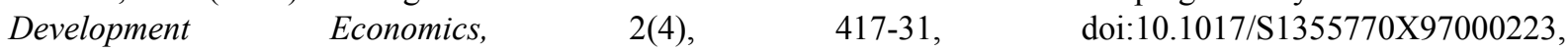
http://dx.doi.org/10.1017/S1355770X97000223

Welsch, H. (2004). Corruption, growth and the environment: a cross-country analysis. Environment and Development Economics, 9, 663-93.

Wei, S. J. (2000). How taxing is corruption on international investors? The Review of Economics and Statistics, $82(1), 1-11$. 
Table 1. Full List of Countries

\begin{tabular}{|c|c|c|c|}
\hline Algeria & Estonia & Malaysia & St. Lucia \\
\hline Argentina & Ethiopia & Maldives & Sudan \\
\hline Australia & Fiji & Mali & Suriname \\
\hline Austria & Finland & Malta & Swaziland \\
\hline Bahamas, The & France & Mauritania & Sweden \\
\hline Bahrain & Gabon & Mauritius & Switzerland \\
\hline Bangladesh & Gambia, The & Mexico & Syria \\
\hline Belgium & Georgia & Mongolia & Tanzania \\
\hline Benin & Germany & Morocco & Thailand \\
\hline Bolivia & Ghana & Mozambique & Togo \\
\hline Botswana & Greece & Nepal & Turkey \\
\hline Brazil & Grenada & Netherlands & Uganda \\
\hline Brunei Darussalam & Guatemala & New Zealand & Ukraine \\
\hline Bulgaria & Guinea & Nicaragua & UAE \\
\hline Burkina Faso & Guinea-Bissau & Niger & United Kingdom \\
\hline Burundi & Guyana & Nigeria & United States \\
\hline Cambodia & Haiti & Norway & Uruguay \\
\hline Cameroon & Honduras & Oman & Venezuela \\
\hline Canada & Hong Kong SAR & Pakistan & Vietnam \\
\hline Cen. African Republic & Hungary & Panama & Zambia \\
\hline Chad & Iceland & Papua N. Guinea & Zimbabwe \\
\hline Chile & India & Paraguay & \\
\hline China & Indonesia & Peru & \\
\hline Colombia & Iran, Islamic Rep. & Philippines & \\
\hline Comoros & Ireland & Poland & \\
\hline Congo, Dem. Rep. & Israel & Portugal & \\
\hline Congo, Rep. & Italy & Qatar & \\
\hline Costa Rica & Jamaica & Romania & \\
\hline Cote d'Ivoire & Japan & Russian Federation & \\
\hline Cuba & Jordan & Rwanda & \\
\hline Cyprus & Kenya & Saudi Arabia & \\
\hline Czech Republic & Korea, Rep. & Senegal & \\
\hline Denmark & Kuwait & Seychelles & \\
\hline Djibouti & Latvia & Sierra Leone & \\
\hline Dominica & Liberia & Singapore & \\
\hline Dominican Republic & Libya & Slovak Republic & \\
\hline Ecuador & Lithuania & Slovenia & \\
\hline Egypt, Arab Rep. & Luxembourg & South Africa & \\
\hline El Salvador & Madagascar & Spain & \\
\hline Equatorial Guinea & Malawi & Sri Lanka & \\
\hline
\end{tabular}


Table 2. Subset of Countries included in the Panel Analysis

\begin{tabular}{|c|c|}
\hline Argentina & Italy \\
\hline Australia & Jamaica \\
\hline Austria & Jordan \\
\hline Burundi & Japan \\
\hline Belgium & Kenya \\
\hline Benin & Cambodia \\
\hline Burkina Faso & Korea \\
\hline Bulgaria & Kuwait \\
\hline Bahrain & Sri Lanka \\
\hline Bahamas & Morocco \\
\hline Bolivia & Madagascar \\
\hline Brazil & Mexico \\
\hline Brunei Darussalam & Mali \\
\hline Central African Republic & Malta \\
\hline Canada & Mongolia \\
\hline Switzerland & Mozambique \\
\hline Chile & Mauritius \\
\hline Chin' & Malaysia \\
\hline Cote d'Ivoire & Niger \\
\hline Cameroon & Nigeria \\
\hline Congo & Netherlands \\
\hline Colombia & Norway \\
\hline Costa Rica & New Zealand \\
\hline Cyprus & Pakistan \\
\hline Djibouti & Panama \\
\hline Denmark & Peru \\
\hline Dominican Republic & Philippines \\
\hline Algeria & Papua New Guinea \\
\hline Ecuador & Poland \\
\hline Egypt & Portugal \\
\hline Spain & Paraguay \\
\hline Finland & Rwanda \\
\hline Fiji & Saudi Arabia \\
\hline France & Sudan \\
\hline Gabon & Senegal \\
\hline United Kingdom & Singapore \\
\hline Ghana & Sierra Leone \\
\hline Gambia & El Salvador \\
\hline Greece & Sweden \\
\hline Guatemala & Swaziland \\
\hline Guyana & Seychelles \\
\hline Hong Kong & Togo \\
\hline Honduras & Thailand \\
\hline Haiti & Turkey \\
\hline Hungary & Tanzania \\
\hline Indonesia & Uganda \\
\hline India & Uruguay \\
\hline Ireland & United States \\
\hline Iran & Venezuela \\
\hline Iceland & Zambia \\
\hline Israel & \\
\hline
\end{tabular}


Table 3. Results for Cross-sectional Analyses, 2007

\begin{tabular}{|c|c|c|c|c|}
\hline $\mathrm{X}_{\mathrm{i}}$ & $\begin{array}{c}\text { Model 1: } \\
\text { Untransformed } \mathrm{CO}_{2}\end{array}$ & $\begin{array}{c}\text { Model 2: } \\
\text { Transformation } 1 \\
\text { Log-linear }\left(\mathrm{CO}_{2}\right)\end{array}$ & $\begin{array}{c}\text { Model 3: } \\
\text { Transformation } 2 \\
\text { Inverse }\left(\mathrm{CO}_{2}\right)\end{array}$ & $\begin{array}{c}\text { Model 4: } \\
\text { Transformation } 3 \\
\text { Square-root }\left(\mathrm{CO}_{2}\right)\end{array}$ \\
\hline GDP & $\begin{array}{l}0.001^{*} \\
(0.000)\end{array}$ & $\begin{array}{l}0.000^{*} \\
(0.000)\end{array}$ & $\begin{array}{c}4.78 \mathrm{E}-005 \\
(0.000)\end{array}$ & $\begin{array}{l}0.000 * \\
(0.000)\end{array}$ \\
\hline GDP_2 & $\begin{array}{c}-1.06 \mathrm{E}-008^{*} \\
(0.000)\end{array}$ & $\begin{array}{c}-3.70 \mathrm{E}-009 * \\
(0.000)\end{array}$ & $\begin{array}{c}3.40 \mathrm{E}-009 \\
(0.000)\end{array}$ & $\begin{array}{c}-2.52 \mathrm{E}-009^{*} \\
(0.000)\end{array}$ \\
\hline GDP_3 & $\begin{array}{c}8.71 \mathrm{E}-014 * \\
(0.000)\end{array}$ & $\begin{array}{c}2.45 \mathrm{E}-014^{*} \\
(0.000)\end{array}$ & $\begin{array}{c}-3.43 \mathrm{E}-014 \\
(0.000)\end{array}$ & $\begin{array}{c}1.68 \mathrm{E}-014 * \\
(0.000)\end{array}$ \\
\hline URBAN & $\begin{array}{l}0.029 \\
(0.021)\end{array}$ & $\begin{array}{l}0.009^{*} \\
(0.004)\end{array}$ & $\begin{array}{c}-.048 \\
(0.026)\end{array}$ & $\begin{array}{c}0.005 \\
(0.003)\end{array}$ \\
\hline FDI & $\begin{array}{c}3.93 \mathrm{E}-011^{*} \\
(0.000)\end{array}$ & $\begin{array}{c}5.63 \mathrm{E}-012 * \\
(0.000)\end{array}$ & $\begin{array}{c}-9.32 \mathrm{E}-012 \\
(0.000)\end{array}$ & $\begin{array}{c}5.82 \mathrm{E}-012 * \\
(0.000)\end{array}$ \\
\hline HDI & $\begin{array}{l}-5.870 \\
(3.777)\end{array}$ & $\begin{array}{l}3.846^{*} \\
(0.720)\end{array}$ & $\begin{array}{l}-20.917^{*} \\
(4.686)\end{array}$ & $\begin{array}{c}0.487 \\
(0.581)\end{array}$ \\
\hline Constant & $\begin{array}{c}0.146 \\
(1.390)\end{array}$ & $\begin{array}{l}-3.386^{*} \\
(0.265)\end{array}$ & $\begin{array}{l}16.531 * \\
(1.724)\end{array}$ & $\begin{array}{l}-0.057 \\
(0.214)\end{array}$ \\
\hline $\mathrm{R}^{2}$ & 0.772 & 0.848 & 0.423 & 0.835 \\
\hline F-statistic & 75.791 & 124.984 & 16.361 & 113.098 \\
\hline No of Obs & 141 & 141 & 141 & 141 \\
\hline
\end{tabular}

Note 1. *Denote significance at 5\% level. Numbers in parentheses are the standard errors.

Table 4. Results for Cross-sectional Analyses, 1970

\begin{tabular}{|c|c|c|c|c|c|}
\hline & $\begin{array}{c}\text { Model 1: } \\
\text { UntransformedCO }\end{array}$ & $\begin{array}{c}\text { Model 2: } \\
\text { Transformation1 } \\
\text { Log-linear } \\
\left(\mathrm{CO}_{2}\right)\end{array}$ & $\begin{array}{c}\text { Model 3: } \\
\text { Transformation } \\
2 \text { Inverse }\left(\mathrm{CO}_{2}\right)\end{array}$ & $\begin{array}{c}\text { Model 4: } \\
\text { Transformation } 3 \\
\text { Square-root } \\
\left(\mathrm{CO}_{2}\right)\end{array}$ & $\begin{array}{c}\text { Model 5: } \\
\text { Transformation } 4 \\
\text { Squared }\left(\mathrm{CO}_{2}\right)\end{array}$ \\
\hline GDP & $\begin{array}{l}-0.005^{*} \\
(0.001)\end{array}$ & $\begin{array}{l}0.001^{*} \\
(0.000)\end{array}$ & $\begin{array}{l}-0.002 \\
(0.003)\end{array}$ & $\begin{array}{c}1.22 \mathrm{E}-005 \\
(0.000)\end{array}$ & $\begin{array}{l}-0.461 * \\
(0.068)\end{array}$ \\
\hline GDP_2 & $\begin{array}{c}2.18 \mathrm{E}-006^{*} \\
(0.000)\end{array}$ & $\begin{array}{c}-9.44 \mathrm{E}-008 \\
(0.000)\end{array}$ & $\begin{array}{c}6.31 \mathrm{E}-007 \\
(0.000)\end{array}$ & $\begin{array}{c}1.56 \mathrm{E}-007 * \\
(0.000)\end{array}$ & $\begin{array}{l}0.000^{*} \\
(0.000)\end{array}$ \\
\hline GDP_3 & $\begin{array}{c}-1.06 \mathrm{E}-010^{*} \\
(0.000)\end{array}$ & $\begin{array}{c}3.19 \mathrm{E}-012 \\
(0.000)\end{array}$ & $\begin{array}{c}-3.36 \mathrm{E}-011 \\
(0.000)\end{array}$ & $\begin{array}{c}-8.80 \mathrm{E}-012^{*} \\
(0.000)\end{array}$ & $\begin{array}{c}-5.66 \mathrm{E}-009 * \\
(0.000)\end{array}$ \\
\hline URBAN & $\begin{array}{l}0.064^{*} \\
(0.022)\end{array}$ & $\begin{array}{l}0.032^{*} \\
(0.006)\end{array}$ & $\begin{array}{l}-0.204^{*} \\
(0.062)\end{array}$ & $\begin{array}{l}0.015^{*} \\
(0.004)\end{array}$ & $\begin{array}{c}2.376 \\
(1.364)\end{array}$ \\
\hline Constant & $\begin{array}{l}1.455^{*} \\
(0.022)\end{array}$ & $\begin{array}{l}-2.418^{*} \\
(0.171)\end{array}$ & $\begin{array}{l}13.829 * \\
(1.756)\end{array}$ & $\begin{array}{l}0.273 * \\
(0.103)\end{array}$ & $\begin{array}{l}161.395^{*} \\
(38.716)\end{array}$ \\
\hline R Square & 0.900 & 0.782 & 0.250 & 0.876 & 0.881 \\
\hline F-statistic & 273.033 & 109.142 & 10.144 & 215.231 & 226.299 \\
\hline $\begin{array}{l}\text { No of } \\
\text { Obs }\end{array}$ & 127 & 127 & 127 & 127 & 127 \\
\hline
\end{tabular}

Note 1. *Denote significance at 5\% level. Numbers in parentheses are the standard errors. 
Table 5. Breusch-Pagan and Normality Tests, 1970

\begin{tabular}{|l|c|c|}
\hline \multicolumn{1}{|c|}{ Model } & $\begin{array}{c}\text { B-P Test }\left(\chi^{2} \text { value }\right) \\
\text { Heteroskedasticity Present? }\end{array}$ & Non-normal errors? \\
\hline $\begin{array}{l}\text { Untransformed: } \\
\mathrm{Y}_{\mathrm{i}}=\beta_{0}+\beta_{1} \mathrm{X}_{\mathrm{i} 1}+\beta_{2} \mathrm{X}_{\mathrm{i} 1}{ }^{2}+\beta_{3} \mathrm{X}_{\mathrm{i} 1}{ }^{3}+\beta_{4} \mathrm{X}_{\mathrm{i} 2}+\varepsilon_{\mathrm{i}}\end{array}$ & Yes. \\
\hline Log-linear $\left(\operatorname{lnC} \mathrm{CO}_{2}\right)$ & $\chi^{2}>100$ & No. \\
\hline Inverse $\left(\mathrm{CO}_{2}\right)$ & $\chi^{2}=8.94$ & Yes. \\
\hline Square-root $\left(\mathrm{CO}_{2}\right)$ & Yes. & Yes. \\
\hline Squared $\left(\mathrm{CO}_{2}\right)$ & $\chi^{2}>100$ & Yes. \\
\hline
\end{tabular}

Table 6. Dynamic Time Series analyses

\begin{tabular}{|c|c|c|c|}
\hline & $\begin{array}{c}\text { Model } 1 \\
\text { Dynamic } \\
\mathrm{CO}_{2 \_} \mathrm{t}\end{array}$ & $\begin{array}{c}\text { Model } 2 \\
\text { Dynamic } \\
\text { Log-linear } \mathrm{CO}_{2} \mathrm{t}\end{array}$ & $\begin{array}{c}\text { Model } 3 \\
\text { Non- Dynamic } \\
\mathrm{CO}_{2 \_} \mathrm{t}\end{array}$ \\
\hline GDP & $\begin{array}{c}0.000 \\
(0.000) \\
\end{array}$ & $\begin{array}{c}-2.46 \mathrm{E}-005 \\
(0.000)\end{array}$ & $\begin{array}{c}0.000 \\
(0.000)\end{array}$ \\
\hline GDP_2 & $\begin{array}{c}2.30 \mathrm{E}-008 \\
(0.000)\end{array}$ & $\begin{array}{c}5.55 \mathrm{E}-009 \\
(0.000)\end{array}$ & $\begin{array}{c}-1.58 \mathrm{E}-008 \\
(0.000)\end{array}$ \\
\hline GDP_3 & $\begin{array}{c}-9.69 \mathrm{E}-013 \\
(0.000)\end{array}$ & $\begin{array}{c}-2.43 \mathrm{E}-013 \\
(0.000)\end{array}$ & $\begin{array}{c}2.16 \mathrm{E}-012 \\
(0.000)\end{array}$ \\
\hline URBAN & $\begin{array}{l}-0.010 \\
(0.030)\end{array}$ & $\begin{array}{l}-0.002 \\
(0.007)\end{array}$ & $\begin{array}{c}-0.087 * \\
(0.031)\end{array}$ \\
\hline $\mathrm{CO}_{2} \_\mathrm{t}-1$ & $\begin{array}{l}0.723 * \\
(0.159) \\
\end{array}$ & & \\
\hline $\ln \mathrm{CO}_{2}{ }_{2} \mathrm{t}-1$ & & $\begin{array}{l}0.725 * \\
(0.158)\end{array}$ & \\
\hline Constant & $\begin{array}{c}1.667 \\
(1.507)\end{array}$ & $\begin{array}{c}0.512 \\
(0.414)\end{array}$ & $\begin{array}{l}7.252 * \\
(1.105)\end{array}$ \\
\hline R Square & 0.759 & 0.754 & 0.599 \\
\hline F-statistic & 19.557 & 19.001 & 11.967 \\
\hline No of Obs. & 37 & 37 & \\
\hline
\end{tabular}

Note 1. *Denote significance at 5\% level. Numbers in parentheses are the standard errors.

Table 7. Dickey-Fuller Tests for Unit Roots

\begin{tabular}{|l|c|c|c|}
\hline \multicolumn{1}{|c|}{ Model } & $\beta_{0}$ & $\beta_{1}$ & $\beta_{2}$ \\
\hline $\begin{array}{l}\Delta \mathrm{Y}_{\mathrm{t}}=\beta_{1} \mathrm{Y}_{\mathrm{t}-1}+\mathrm{e}_{\mathrm{t}} \\
\text { (no intercept) }\end{array}$ & & 0.004 & \\
\hline $\begin{array}{l}\Delta \mathrm{Y}_{\mathrm{t}}=\beta_{0}+\beta_{1} \mathrm{Y}_{\mathrm{t}-1}+\beta_{2} \mathrm{t}+\mathrm{e}_{\mathrm{t}} \\
\text { (with intercept) }\end{array}$ & -1.845 & -0.100 & $0.004)$ \\
\hline
\end{tabular}

Note 1. *Denote significance at 5\% level. Numbers in parentheses are the standard errors. 
Table 8. Panel Analysis with Fixed Effects Results, 1970-2007

\begin{tabular}{|c|c|}
\hline & $\begin{array}{c}\text { Model } 1 \\
\text { Panel Analysis } \\
\text { CO2 }\end{array}$ \\
\hline GDP & $\begin{array}{l}0.000113457^{*} \\
(5.03075 \mathrm{e}-05)\end{array}$ \\
\hline GDP_2 & $\begin{array}{l}-9.25588 \mathrm{e}-09^{*} \\
(2.42428 \mathrm{e}-09)\end{array}$ \\
\hline GDP_3 & $\begin{array}{c}1.25494 \mathrm{e}-013^{*} \\
(0.000000)\end{array}$ \\
\hline URBAN & $\begin{array}{c}-0.0713085^{*} \\
(0.0105532)\end{array}$ \\
\hline FDI & $\begin{array}{l}-6.82526 \mathrm{e}-013 \\
(4.89836 \mathrm{e}-012)\end{array}$ \\
\hline HDI & $\begin{array}{l}19.7347^{*} \\
(1.64904)\end{array}$ \\
\hline Constant & $\begin{array}{l}-2.91851 * \\
(0.759397)\end{array}$ \\
\hline R Square & 0.830173 \\
\hline F-statistic & 170.0780 \\
\hline No of Obs & 3,795 \\
\hline
\end{tabular}

Note 1. *Denote significance at 5\% level. Numbers in parentheses are the standard errors. 